Civil Engineering

Volume 170 Issue CE4

Crossrail project: the evolution of an innovation ecosystem

Pelton, Brown, Reddaway et al.
Proceedings of the Institution of Civil Engineers Civil Engineering 170 November 2017 Issue CE4 Pages 181-190 http://dx.doi.org/10.1680/jcien.16.00036 Paper 1600036

Received 22/09/2016

Published online 24/04/2017 Keywords: knowledge management/procurement/ project management

Published with permission by the ICE under the CC-BY license. (http://creativecommons.org/licenses/by/4.0/) ited

\title{
Crossrail project: the evolution of an innovation ecosystem
}

1 John Pelton MBE, FICE, FlnstRE Director, $\mathrm{CH} 2 \mathrm{M}$, London, UK

2 Maggie Brown BA, MSC Innovation Manager, Hinkley Point C, EDF Energy, Bristol, UK

3 Will Reddaway BEng (Hons) Group Head of Innovation, J Murphy \& Sons Ltd, London, UK

4 Marie Gilmour BEng (Hons), MAPM Consultant, Nichols Group, London, UK
5 Syinyi Phoon PhD, CEng, MICE Project Manager, CH2M, London, UK

6 Andrew Wolstenholme OBE, FREng Chief Executive, Crossrail Ltd, London, UK

7 David Gann CBE, CEng, FICE, FCGI Vice President - Innovation and Professor, Imperial College London, London, UK
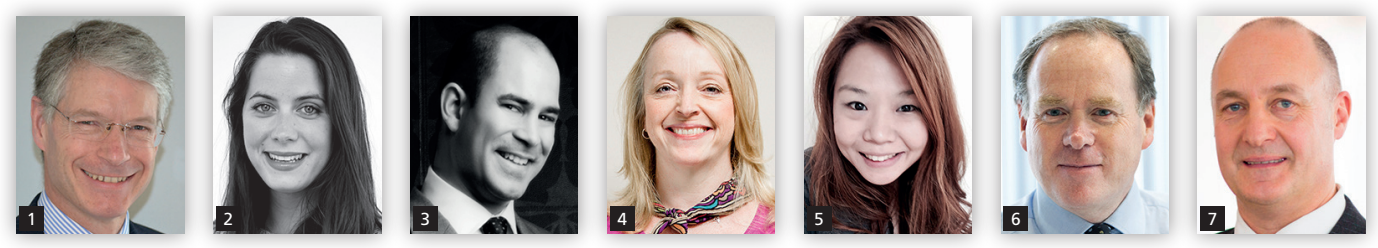

The $\mathbf{f 1 4 . 8}$ billion Crossrail project to deliver the Elizabeth line east-west railway across London has pioneered the development of a systematic programme approach to innovation. Previous papers have focused on the early stages of setting up Crossrail's innovation programme - known as Innovate18 - and implementing it as a credible component of the delivery organisation. With the Elizabeth line now close to completion there is an opportunity to reflect on the project's experience of innovation and the performance of its programme as it reaches maturity. This paper describes the maturing programme, lessons that have been learned and how the programme has migrated into an infrastructure industry platform.

\section{Introduction}

Calls for greater innovation in the UK's built environment industry have been steadily increasing since the reports by Latham (1994), Egan (1998) and Wolstenholme (2009). Evidence of an increased focus on innovation emerged during the London 2012 Olympic and Paralympic Games venues and infrastructure programme as well as during construction of Heathrow airport Terminal 5 (Davies et al., 2016). The innovation programme on the Crossrail project to deliver the Elizabeth line east-west railway across London - known as Innovate18 - has now provided the first example of a systematic approach to innovation on a major infrastructure project.

Crossrail's strategy (Crossrail, 2013: p. 7) defined innovation as 'the successful commercial exploitation of new ideas: the scientific, technological, organisational, financial, and business activities leading to the commercial introduction of new or substantially improved products, processes, services or entire business models' (Crossrail, 2013). Davies et al. (2014) described how innovation took place during the project's 'leveraging' window while DeBarro et al. (2015) described how the innovation strategy was converted into practice at the start of the innovation programme, and the strategy and processes that comprise the innovation programme.

As the Elizabeth line moves into the 'exchanging' window (Davies et al., 2014), this paper draws on the experience of the latter stages of the innovation programme and has been written by the leaders and practitioners responsible for developing the theory into practice. The paper's first section summarises the innovation programme to provide context and as a record of progress. The second section considers specific areas that have provided challenge and opportunity for the programme and its team. The final section considers how experience on the project is being shared across the industry and outlines the initial stages of an emerging industry approach building on the Crossrail innovation programme.

\section{Innovation programme}

The Elizabeth line is Europe's largest construction project with a total funding envelope of $£ 14 \cdot 8$ billion (Crossrail, 2016). The project started in 2009 and passenger services through central London will start running in late 2018. In 2012, project undertaker Crossrail recognised an opportunity for a pioneering approach to innovation with idea sharing as a key design principle. It was structured around three overlapping themes: life-cycle efficiencies, digital-physical integration and sustainable solutions. A fourth theme, health and safety, was added in 2015, reflecting its significance on this large and complex project.

In partnership with Imperial College an innovation strategy was developed (Crossrail, 2013), which set out the vision (Figure 1) and was based around three 'Cs': collaboration, culture and capability. Of these, collaboration is key, enabled by the unique programme funding mechanism set in the context of the NEC3 Engineering and Construction Contract main works contracts. Each of the tier 1 contractors' chief executives or managing directors was personally invited by Crossrail's chief executive to join the innovation programme by investing $£ 25000$ and agreeing to participate in the open-sharing 'ecosystem'. Crossrail match-funded these investments and shared the ideas, innovations and benefits. 


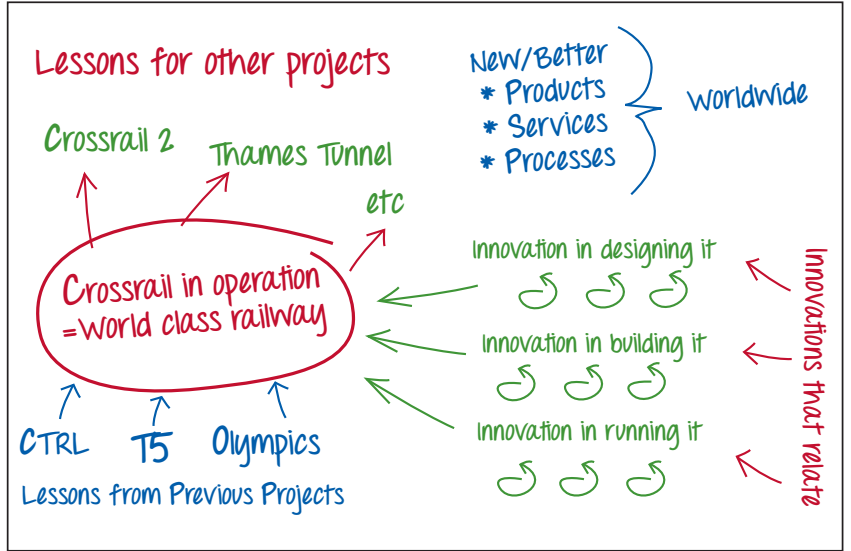

Figure 1. Innovation programme vision

A small, four-strong, innovation team was established under the strategic projects director to bring the innovation programme to life across the project. It established an innovation network across Crossrail, its partners and the supply chain, brought together by a common desire to test new ideas in an open-sharing environment. The mantra was 'pinching with pride' - ideas could be 'pinched' provided they were improved and the results shared. The innovation programme provided a 'safe place' to innovate and test ideas.

All activity was enabled by the innovation programme web portal, which allowed ideas to be uploaded, shared and discussed by way of blogs and discussion forums, underpinned by a relational database. The portal became a key sharing mechanism for the project. Finally, a 'light touch' governance process was established to agree the ideas that required funding from the innovation fund. The resulting 'mini-projects' were intended to be delivered by innovation champions and innovators with oversight from the innovation team.

\section{Innovation team}

The innovation strategy was anchored in collaboration and the collective benefit from sharing ideas. Therefore, people were central to the concept and hence the innovation team's role was vital to the success of the programme.

The team needed the right conditions for them to operate effectively. In particular, they required strong commitment from senior leadership. At the highest level this came from the chief executives and managing directors of the companies involved in Crossrail, who expressed a collective desire for change in the way the industry addressed innovation, and demonstrated their support for the innovation programme through committing funds. However, energising support from the people on the ground was also critical to delivering results. The innovation team (Figure 2) had to have drive, enthusiasm and perseverance to energise people, find ways around innovation obstacles and overcome the innate scepticism of the industry. While some of the team members were technologists and engineers, it was their people skills that were essential in enabling them to influence, support and persuade people to innovate.

The team's key role was to engage a network of innovation champions and innovators and then to support the network in

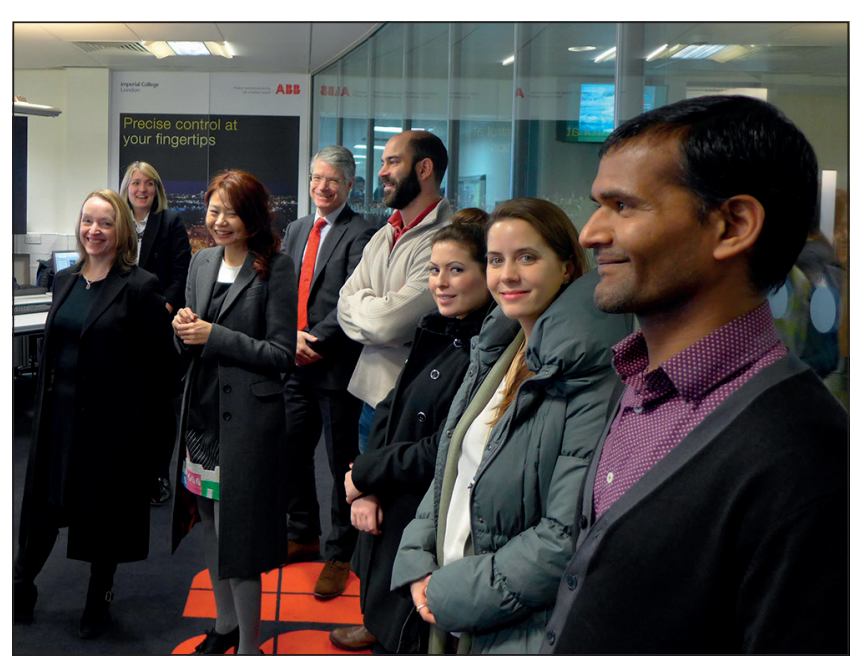

Figure 2. Innovation programme team

delivering ideas and innovations. Take-up was by no means uniform and the team was heavily dependent on the enthusiasm and commitment of over 100 innovation champions. These were drawn from various organisations including the contractors, consultants, partners and Crossrail staff. It worked best when supported by project managers, even if only tacitly.

When there was a groundswell of support, it was quickly realised that people needed help to maximise the effectiveness of the innovation programme opportunity. The innovation team has led creative thinking workshops, solution-focussed sessions and demonstrations to help people understand how they could enhance their ability to generate ideas and deliver innovation. Nurturing, encouraging and supporting the community of innovation champions and innovators across the project, and providing them with the skills needed, were all vital to the success of the programme.

The innovation team itself soon found that it also needed support and training in developing the skills required to engage people and enable effective innovation. Individual and team self-awareness was greatly enhanced by using personality inventories (the innovation team used the Myers Briggs type indicator (The Myers \& Briggs Foundation, 2016)). However, it was found that regular 'chartering' sessions using 'solution-focus' techniques were the best way of rapidly building a strong, visionary and resilient team capable of leading this challenging programme (solution focus is a goaldirected collaborative approach to building a high-performing team around a common purpose).

Developing a delivery strategy, implementing sprint actions and ultimately drawing the programme to an end were all conducted as highly collaborative team exercises. The strength of the innovation team is important: the innovation role is unrelenting and can be exhausting. Renewal either by replacement or through re-chartering was a constant and necessary feature of the innovation programme.

\section{Governance}

Achieving the right level of governance was critical: too much and innovation could be stifled; too little and the loss of control 
and consistency could undermine its credibility. The innovation programme governance (Figure 3) was, therefore, designed to provide an agile mechanism for responding to innovation proposals while retaining a sufficient accountability for the level of funds being expended in line with project governance processes.

Lessons were learned. The prototype Crossrail Innovation Working Group included only three tier 1 contractors. This was an early compromise to enable the group to operate at the start of the programme. However, it excluded much of the community and undermined the principle of collaboration. Therefore, from mid2015, all 16 Crossrail tier 1 contractors supporting the innovation

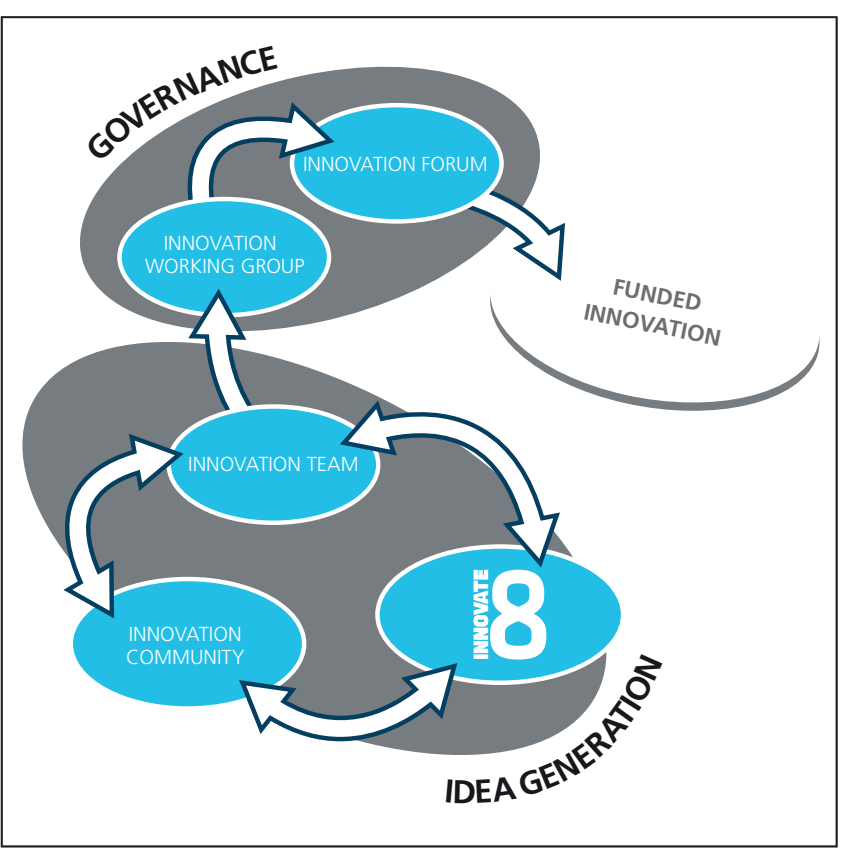

Figure 3. Innovation programme governance process

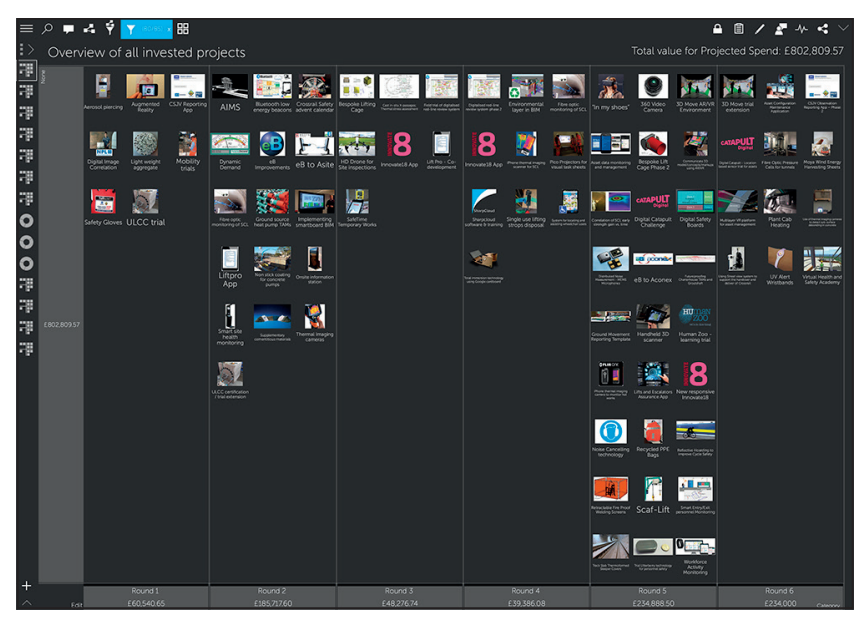

Figure 4. Sharp Cloud software dashboard showing funded innovations and used by the innovation working group as a decision-support tool programme were invited and were consistently well represented for the remainder of the programme. With the right preparation, managing such a large and diverse group was achievable, and included innovations, such as electronic voting, to enable timely process.

The Crossrail Innovation Forum provided strategic direction and a programme-level overview. Quite rightly, the forum was careful to ensure that the funds being invested would realise the best value for the programme. However, the overall level of investment sends a powerful message to the innovators. It was found that there was a tendency for the forum to become overly focused on specific innovations. During 2015, two successive forums significantly reduced the rate of investment (Figure 4).

The situation was later recovered by maximising the use of the team's delegation and by focusing the team's effort on the invested projects. However, the combined effect of slowing down the investment rate together with reducing the time the team was able to spend with the innovation community was assessed to be a key factor in the steady fall-off of innovation rates during the second half of the programme (Figure 5).

\section{Delivery}

The transition of ideas into innovations proved more challenging than expected. Many ideas could be implemented by site teams with little or no additional resources. However, there was a significant number, including many that required investment, which became small projects in their own right.

It had been expected that the innovators and/or their organisations would manage these. However, it soon became apparent that this was not taking place. Furthermore, as the understanding of the innovation process developed it was clear that the different stages of the process (Figure 6) required different management techniques.

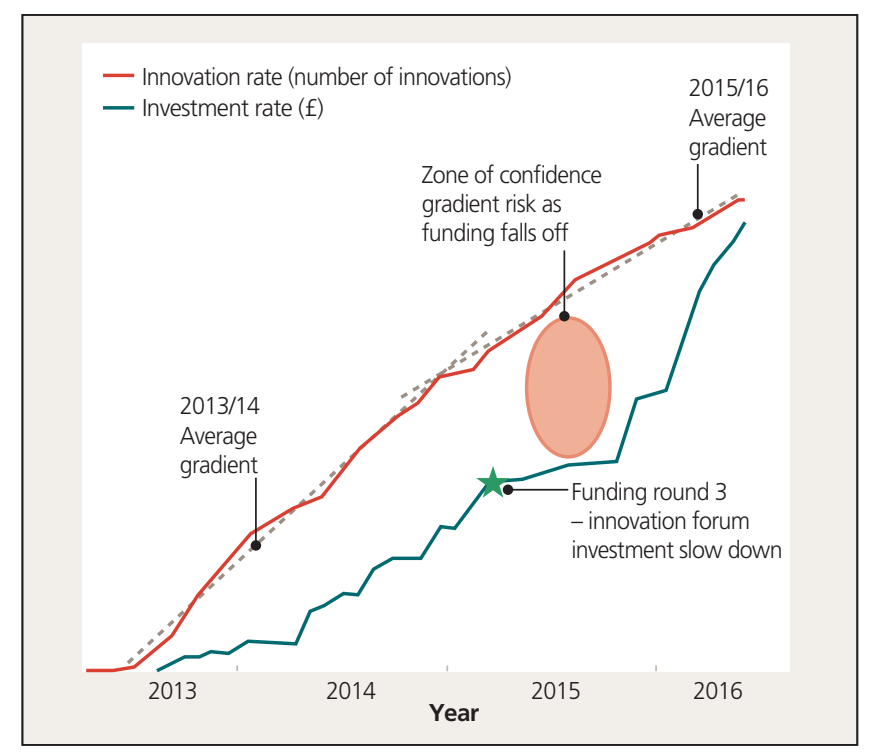

Figure 5. Comparison of the innovation funding rate with the innovation rate over the duration of the innovation programme 


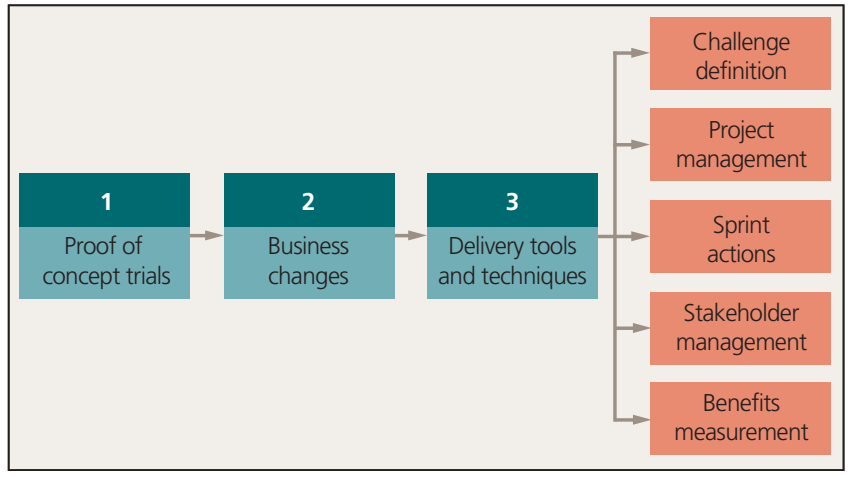

Figure 6. Three stages involved in developing an idea into an innovation on the innovation programme

\subsection{Stage 1: proof of concept trials and feasibility trials}

Where an idea was put forward for which benefits were unproved in the proposed context, the innovation team was able to support innovators in designing a trial and in particular defining its boundaries. Figure 7 shows an example of an innovation submission.

Trials could be outsourced and funded by the innovation fund or conducted by innovation programme members. A number of trial planning factors were developed and shared to improve the process (Figure 8). The outcome allowed a strategy for developing to the next delivery stage, referring back to the Crossrail Innovation Working Group as required for additional funding.

\subsection{Stage 2: business change ideas}

Most innovations required some associated business change: some were business process innovations. An understanding of the business benefit is key at this stage, accepting that in many cases the benefits could be soft benefits or indirect benefits in the form of soft de-risking of activities rather than a direct cost or time saving per se. However, this also became another demand on the project management process.

Understanding the need for effective baselining led the innovation team to work together with, among other things, six sigma teams from Crossrail and the supply chain to improve understanding and capture the potential efficiency gains from ideas.

\subsection{Stage 3: delivery tools and techniques}

As the innovation programme progressed, the wide variety of ideas generated by the innovation community became apparent. For some the approval to take action was sufficient, while others could be implemented by the innovator with a small injection of funding.

However, many required a more formal approach to ensure that funds were spent efficiently, to enable procurement processes, to engage all those that needed to be involved or simply just to manage a more complex change.

\section{Lessons learned}

\subsection{Challenge definition}

It is axiomatic that 'a problem well stated is a problem halfsolved' (Charles Kettering, 1876-1958). The innovation team

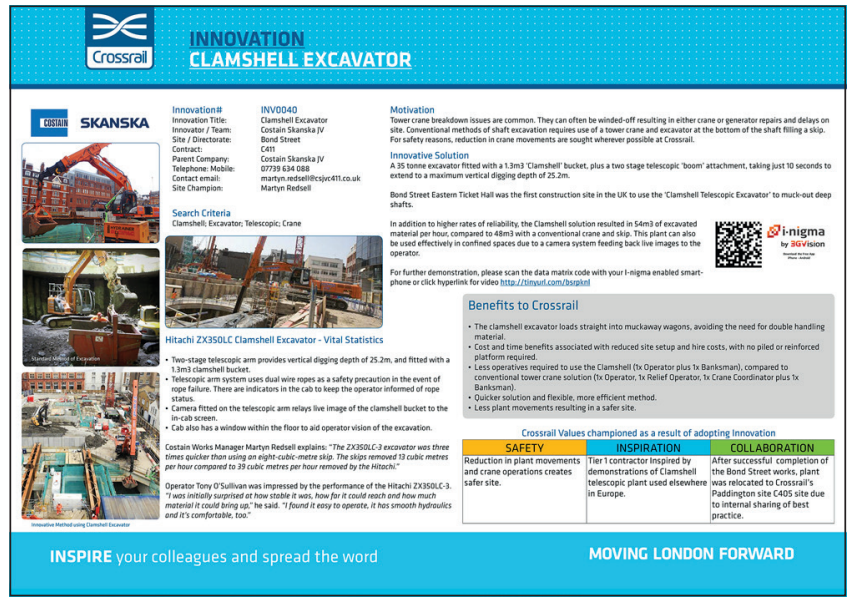

Figure 7. An example of an initial idea submission from the innovation programme portal - the clamshell telescopic excavator

\section{Concept trial planning factors}

What is the business challenge that is being addressed?

What are the anticipated benefits: value, cost?

Outcomes - what tangible outcomes are hoped for?

Resources - what materials, people, access to site, equipment are required?

Environment - what method statements are required?

Measurements - how will the outcomes be measured?

Dependencies

Outputs - typically a report, recommended next steps

Figure 8. Concept trial planning factors developed from experience of innovation on Crossrail

realised that the key step of testing the challenge with sufficient rigour was not being done effectively. They developed their own skills in vision-led solution-focus analysis and creative thinking techniques, such as boundary examination (Van Gundy, 1988) or multiple redefinition (Rickards, 1974).

The greater the collaboration at this stage, the greater the subsequent engagement and commitment in delivering the innovation.

\subsection{Project management}

Standard approaches to project management, such as the Association for Project Management Body of Knowledge (APM, 2016) were adopted, with controls tailored to ensure fitness for purpose and agility. In some cases the project management was led by contractors or Crossrail project teams. However, these often lacked sufficient resources. Therefore, the weight of effort routinely fell back onto the innovation team, which was neither configured nor resourced for this task.

One solution was to increase the size of the innovation team, such as through an additional team member for 6 months during 2014 , which enabled a number of projects to be completed. Another was to devolve the routine innovation activity to the innovation community and release the innovation team to manage projects. 
However, the maturity level of the community, increasingly being eroded by staff turnover, was not sufficient and this contributed to a reduction in the rate of innovation.

\subsection{Procurement}

The procurement of innovation solutions proved a consistent challenge. The innovation programme tended to involve very small levels of expenditure to test ideas, which were then processed through a procurement system configured around major works contracts using competitive selection. The procurement process time, while not unreasonable by industry standards, was often too slow for the innovation programme's requirements.

Competitive solutions were often inappropriate for early stage innovations. Once the procurement and innovation teams understood each other's needs, the situation improved. Some innovative procurement ideas, such as brokering (see Section 9 ), were tried out. However, procurement challenges tended to exacerbate the 'bow wave' of project work required to deliver funded innovations and proved a consistent problem for the innovation team's limited resources.

A further procurement issue was whether or not to instruct tier 1 contractors to implement innovations. From a contractor's perspective, this could enable easier procurement of subcontracted work and provide clarity of responsibility. From Crossrail's perspective, it could add additional cost. Each issue was taken on its merits. With the benefit of hindsight, it is now clear that this can be better understood in terms of risk and opportunity.

Where the contractor was better placed to realise the opportunity - for example, innovations that would directly improve efficiency and enhance gain share - then instructing was not the best solution. However, when the benefit was, for example, programme-level risk mitigation, the client was generally better placed to manage the risk and could issue an instruction. Health and safety and sustainability were two areas where this was often appropriate.

\subsection{Competition}

During 2015, the innovation team trialled a competition-based approach. Up to $£ 30000$ was allocated to invest in ideas and innovations that arose from a competition to provide health and safety solutions. The competition was coordinated with the project's health and safety stepping up week in April 2015 and aligned with key safety themes.

It resulted in the development of a health and safety software application (Figure 9), a three-dimensional interactive training system to enable mission rehearsal and a range of other safetyrelated activities. Overall, it was a very positive experience. However, it required a significant amount of effort, which at times threatened to distract the innovation team from the main programme, although this was mitigated by the involvement of the health and safety team.

A key lesson from the experience was the value of functional teams, such as health and safety or sustainability, taking the lead in exploiting innovation.

\subsection{Information technology}

Initially, basic, off-the-shelf, collaboration software was chosen. This decision proved to be sound, providing an easy-to-use and

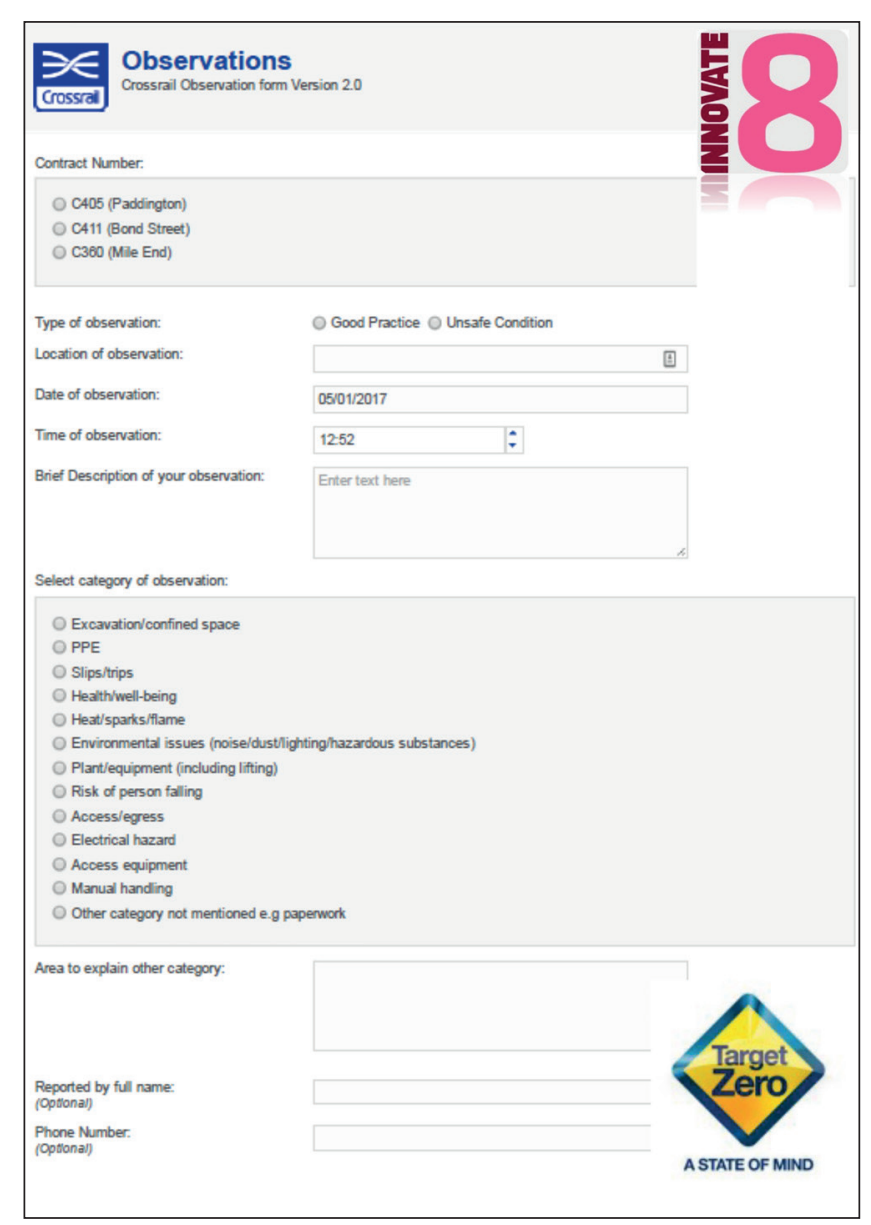

Figure 9. Health and safety innovation in action - the health and safety application, which allows near-miss and other health and safety reporting to be done using smart phones, tablets or computers, making the process easier and increasing the reporting rate to enhance site safety

quickly deployable solution that met the requirements, while avoiding excessive cost. However, it proved difficult to adapt in response to the lessons learned by its use.

Therefore, in 2016, it was decided to move from the original platform, which utilised basic document (pdf) sharing and discussion forums, to one utilising dynamic web pages, modern and more interactive software.

The new platform worked more efficiently and enabled the innovation community to use the portal from multiple devices (personal computers, smartphones or tablets). The source code is now available from the Crossrail Learning Legacy website innovation page (Crossrail Learning Legacy, 2016).

\subsection{Communications strategy}

With a large network of innovators (over 1000) and the involvement of a growing number of organisations in the innovation programme, it became apparent that a formal communications plan was essential.

The innovation team, in conjunction with Crossrail's internal communications team, produced videos and brochures (Figure 10), 
delivered presentations and briefings and hosted events to mark and celebrate the successes of the programme.

The coordinated effect ensured a greater awareness of innovation and supported the activities of the team in delivering benefits from innovation on the project.

\section{Benefits}

When the innovation programme was conceived in 2012, the primary goal was to establish it and demonstrate its concept on a major infrastructure project. The benefits of specific ideas and innovations, and of the programme as a whole, were considered secondary issues. However, as the innovation programme established itself the issue came to the fore, both in terms of assessing the performance of the programme on the project and also for other projects in considering whether to adopt a similar approach.

Ideas submissions through the innovation programme portal included a statement of the potential benefits to the project. However, this is only a short, 2000-character, text field. In particular, innovators have not been required to define the current baseline against which the benefits might be measured, such as time or cost.

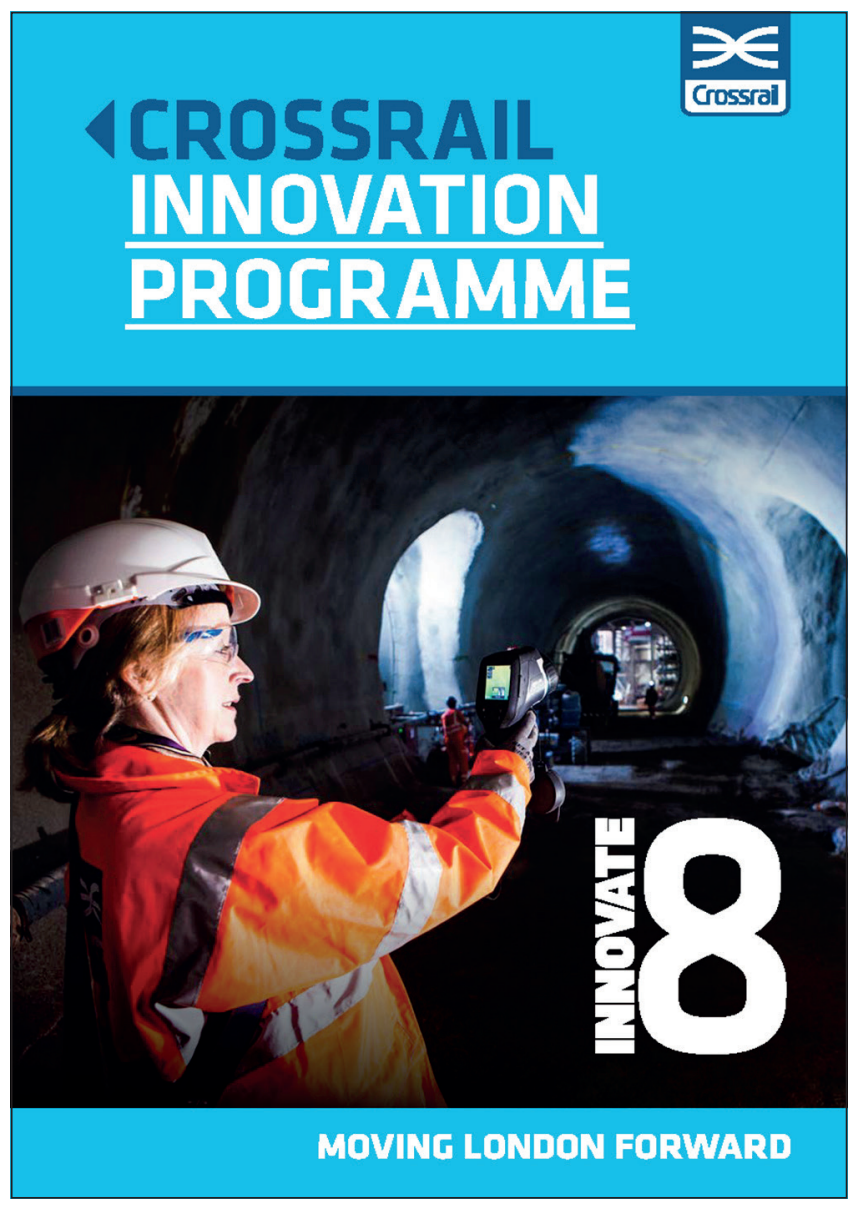

Figure 10. Innovation programme brochure published in 2015 to provide an update on the programme's progress
Therefore, many of the earlier ideas submitted did not include sufficient evidence to form a baseline against which to develop benefit to cost ratios. That is not to say that benefit was not being delivered. There was clear evidence that people were using the innovation programme portal to share best practices, lessons learned and some genuinely clever solutions to problems they had faced on their individual projects.

The innovation programme demonstrated that a collaborative innovation culture could be developed on a mega-project such as Crossrail and that companies and clients were prepared to share ideas for collective benefit. The innovation programme caught the imagination of many of the bright young members of the project, providing a valuable mechanism for attracting and retaining talent. The innovation programme also contributed to Crossrail's broader reputation as a project that welcomes innovation and encourages its supply chain to deliver innovative solutions, drawing on their own company innovation programmes (Figure 11).

In seeking to define time/cost benefits, the innovation programme tested the use of the six sigma tool for process improvement in assessing the benefit value from innovations. Where the data were available, this proved a useful tool. In addition, it became evident from this experience that there was also a significant synergy to be had between, for example, six sigma and the more creative techniques inherent in the innovation programme18 approach.

Benefits were also described in terms of overall programme performance, including total innovation rates (Figure 11), the percentage of shares to submissions (the basis of the Crossrail programme key performance indicators for innovation) (DeBarro et al., 2015) and a correlation between contract performance and innovation (Figure 12).

However, cost remains the make or break factor for many people. Therefore, in 2015 Imperial College was commissioned to conduct

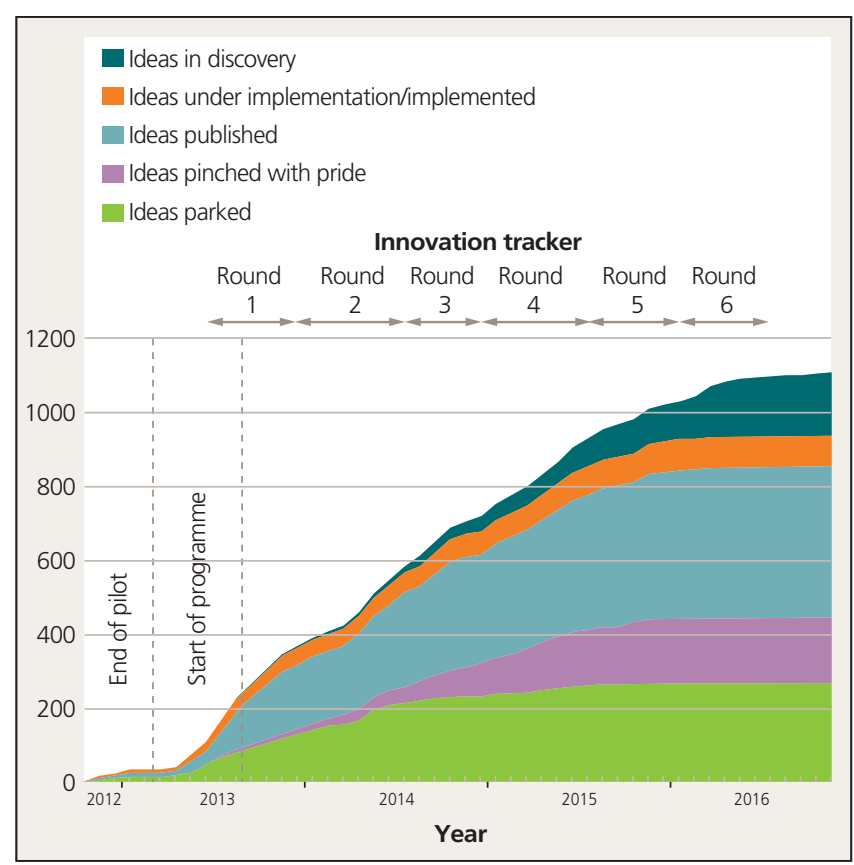

Figure 11. Innovation rates for the duration of the innovation programme 


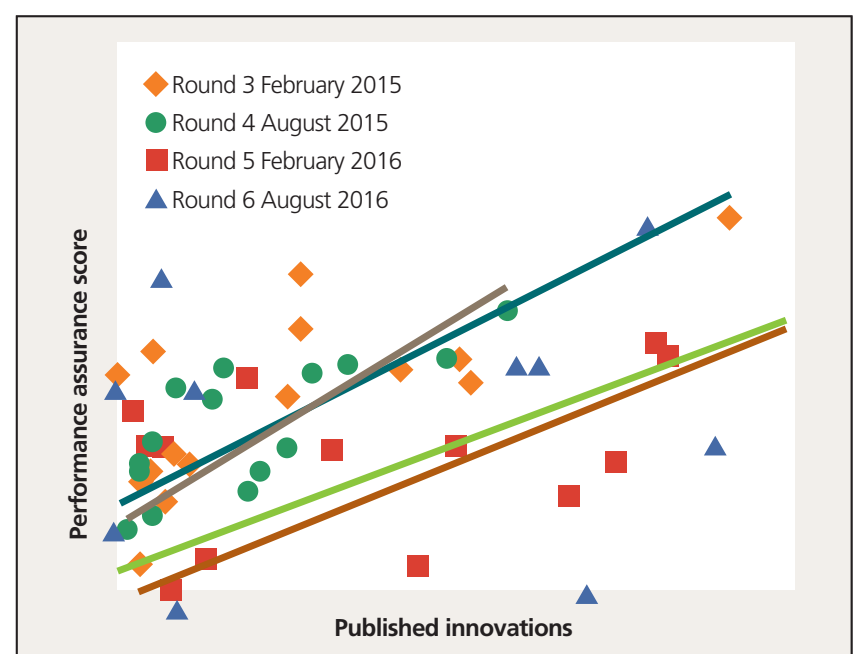

Figure 12. Performance assurance data for innovation, comparing a generic performance indicator with published innovations at 6-monthly intervals between February 2015 and August 2016

an independent study to assess the benefits due to the innovation programme. The results (Vernet, 2016) reinforced the soft evidence by showing a benefit-cost ratio of around 2:1 (benefits realised by mid-2015 compared with costs for the whole innovation programme through to the end of 2016).

Owing to the initial lack of baseline data, only 299 out of the 800 ideas submitted were able to be assessed. Only ideas such as the lifts and escalators computer application (Figure 13), which originated from the innovation programme, were considered. Finally, the innovation programme was implemented 4 years after the start of major construction work and, therefore, the innovation effort was focused on the construction process rather more than on engineering innovation at the design and planning stages.

Nevertheless, extrapolating the benefits to the end of the programme (December 2016) suggests that the overall benefitcost ratio will exceed $3: 1$, giving direct savings from the limited selection of innovations in excess of $£ 10$ million.

The experience of the innovation programme showed the value of performance measurement in highlighting the soft benefits of innovation. However, a key lesson has been the need to define a baseline for assessing tangible benefits from ideas and innovations as early as possible, and to include even a simple cost model in the on-line submission process. The trick is to collect these essential data without it becoming a tool for switching off specific ideas and innovations at too early a stage.

\section{Incentives}

Incentives for the innovation programme operated at a number of levels. For individuals, the assumption that creating the conditions for people to innovate and providing the resources to develop their ideas rather than personal remuneration would trigger innovation was justified by $10 \%$ of the entire workforce engaging with the programme.

Contractors were incentivised twice over. First, there was a clear desire on behalf of contractors to be part of this pioneering

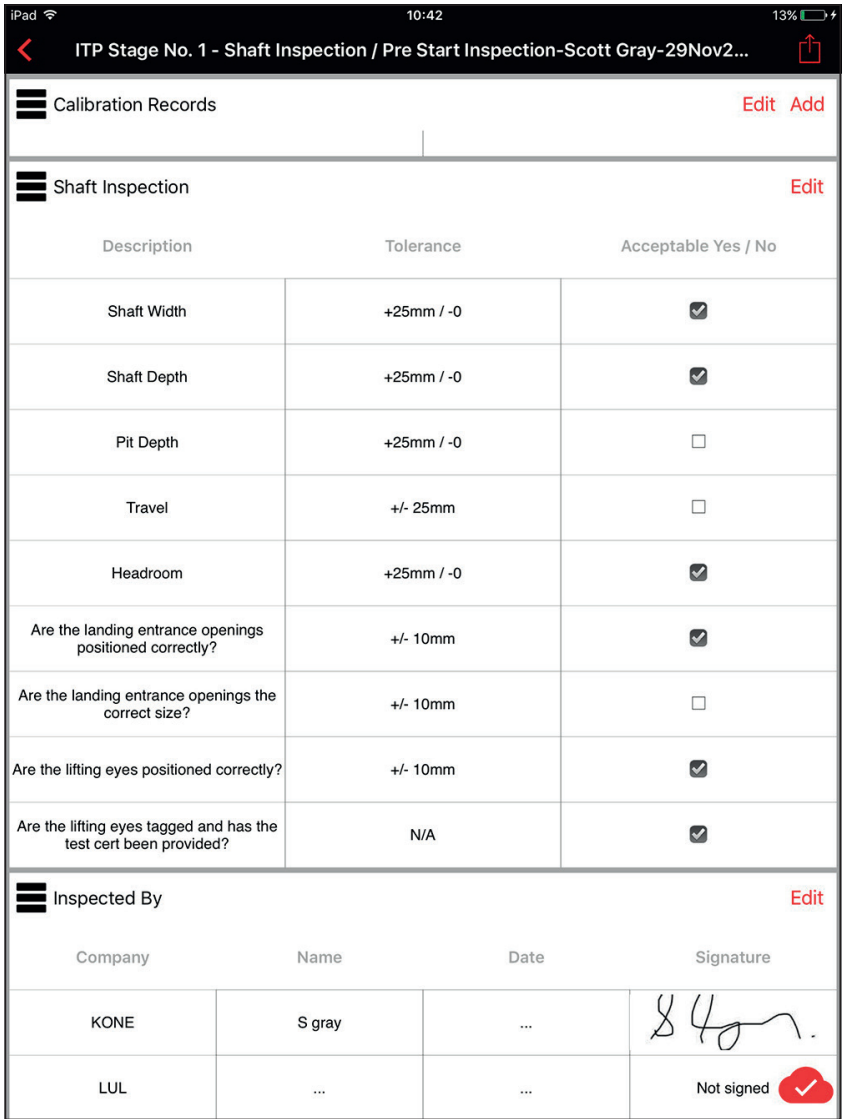

Figure 13. The lifts and escalators application, which combines automatic forms with an electronic workflow to speed up the approvals process for lifts and escalators

initiative. There was a strong sense that they wanted to see their match-funded $£ 25000$ contribution invested wisely. The direct cost and time savings resulting from the innovations accrued to the contractors in the first instance and were then shared through the 50:50 gain-share mechanism inherent in the NEC3 contracts. While there was no formal contractual commitment to the innovation programme, largely because most contracts had been let prior to the start of the programme, it is clear that a commercial driver is the key to enabling the supply chain to commit. Future projects should seek to exploit this from the start, by integrating innovation incentives.

At a Crossrail level the situation was less clear. The chief executive and some of his executive team were passionately committed to the innovation programme and provided outstanding leadership. However, despite the mounting evidence of a range of benefits, there was no real incentive for the executive members to commit to the programme.

During 2014/2015 there was a Crossrail programme key performance indicator for innovation, but at $2 \%$ and later reducing to $1 \%$ of the total it made almost no material impact in motivating performance. This compares with safety at $23 \%$ of the whole and a real behaviour driver. As a result, there was no flow-down of innovation targets by way of the directors' and project managers' performance assessments. Integrating innovation into personal targets could have helped to establish innovation as a core project 
function rather than it remaining on the periphery, as it tended to do on the project despite the effect of the innovation programme.

To reinforce the performance incentive, experience from Crossrail suggests that some delegation of innovation funds to project managers would provide them with some resources to allow them to meet their innovation targets. This should be something that future innovation programmes consider.

\section{Small and medium enterprises}

Small and medium enterprises (SMEs), such as Base Stone, which developed the 'red line app' (Figure 14), were actively involved in the innovation programme and perceived as a rich seam of innovation potential. However, exploiting this potential has proved challenging.

SMEs have difficulty in finding a gatekeeper on major projects, they find the bureaucracy unmanageable, and they are exposed to procurement processes which can undermine their intellectual property. For example, Crossrail initially required the novation of all software licences to itself. The innovation programme team asked for the clause to be removed as it prevented SMEs from bringing application-based innovation onto the programme.

Equally, major projects (and large organisations) are unsure how to identify SME expertise and are cautious of committing at the first contact with an SME as they try to understand how to set up a competitive environment and seek best value.

SMEs can also require significant project resources to support them. Often SMEs are very young organisations that are operating in a fast-changing technical context but lack the financial robustness or have not been in existence long enough for Crossrail's procurement rules.

The innovation programme sought to address the conundrum and to enable the innovative potential of the SME community to be tapped in a number of ways. The innovation programme itself provided a more streamlined vehicle for SMEs to work with Crossrail. The initial approach taken was to encourage SMEs to

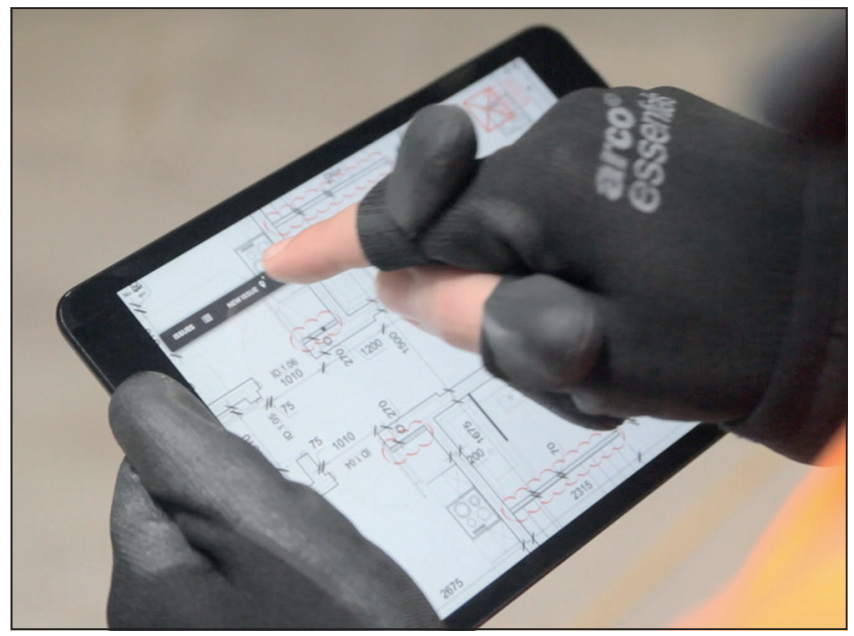

Figure 14. The red line application, which enables an operator to conduct red-lining using a tablet interfacing directly with the central building information modelling database contribute by way of the tier 1 contractors. This avoided some of the direct interface difficulties, although some of these also characterise the relationship between SMEs and the contractor organisations.

However, not all SMEs were comfortable operating with contractors. In addition, as the increasing prevalence of digital solutions began to emerge, there were many SMEs that the contractors themselves were not yet aware of.

Another approach was to develop a brokering arrangement (Figure 15), in which an external organisation with knowledge of and access to the SME network provides a brokering service in response to the innovation team's requirements defined on behalf of Crossrail. The model that developed involved the team in effect acting as the broker for the tier 1 contractors and to facilitate any funding that might be made available from the innovation fund.

A number of brokering organisations exist, mostly in the not-forprofit sector. However, the novelty of this approach combined with the expected fees at a relatively late stage in the Crossrail project, and hence low confidence in the return on the investment, meant that this approach foundered.

A variation on the brokering model was trialled in conjunction with the Digital Catapult - an organisation established by Innovate UK to support digital innovation - using its 'pit stop' model. This brought together a selected group of SMEs with experts from Crossrail and representatives from the supply chain to address a digital challenge set by Crossrail (Figure 16).

The 'pit stop' was a one-off event that took place over 2 days, which provided a cost-effective way of testing the model. It involved an explanation of the challenge, a collaborative analysis to unpack the issues, a series of brainstorming sessions to develop ideas to address the challenge and a selection process to narrow down to a manageable number of ideas to be explored further. The SMEs, either independently or in conjunction with others, were then invited to submit a proposition to the innovation programme to be considered for possible investment by the programme.

The feedback from all involved was very positive. Holding the event at a relatively late stage in the project limited the scope for those attending to provide timely solutions. However,

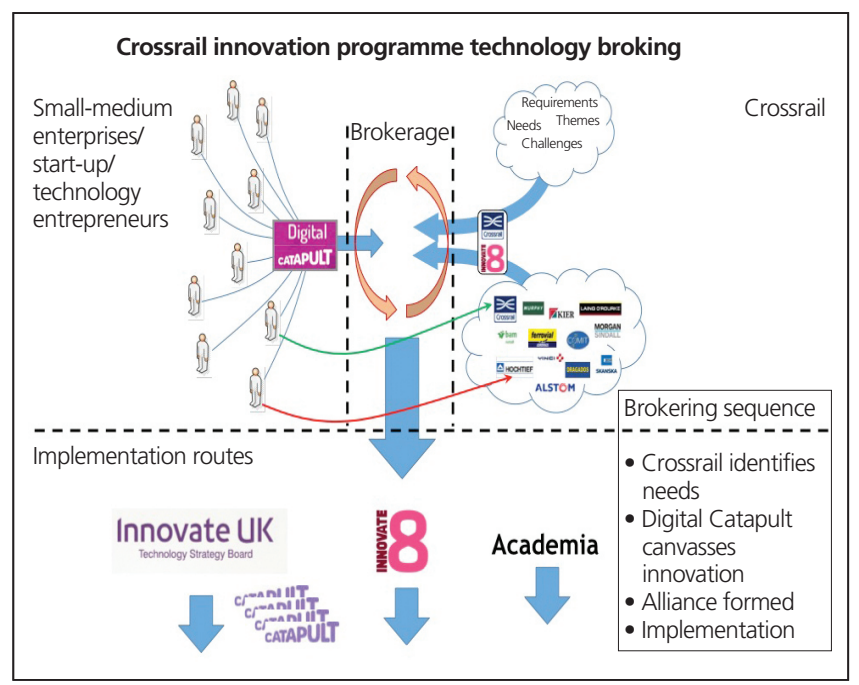

Figure 15. Innovation brokering concept as trialled in conjunction with Digital Catapult 


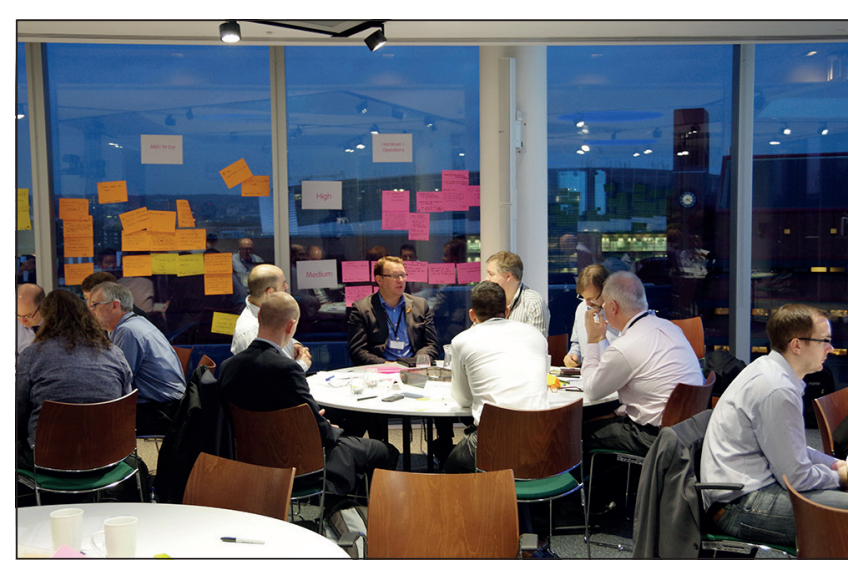

Figure 16. Brokering in action - the Crossrail/Digital Catapult pit stop

it demonstrated the value of such a collaborative event for engaging SMEs and the project community in a practical and effective way.

One final method was tested by the innovation team when it contributed to an architecture, engineering and construction 'hackathon' run by Innovate UK. The innovation team provided a digital challenge around data assurance and presented to those attending to provide the necessary background on the project. In return around 40 attendees spent a weekend coding and developing software and applications to provide a solution. The idea was that this would provide sufficient competition to enable the winners to be offered a short contract to carry out a pilot project to prove the concept.

There is certainly potential in the approach. It allows new ideas and techniques to be rapidly developed and allows SMEs to engage with major project staff. However, the lack of formed entities (the winning teams formed only for the weekend) and the immaturity of the project knowledge among those involved limited its value.

\section{Industry legacy}

If 'imitation is the sincerest form of flattery' (Colton, 1824: p. 114) then Crossrail's innovation programme is performing well. The UK's High Speed Two north-south rail project and the Thames Tideway sewer tunnel project in London are both developing innovation programmes. Other UK clients including Network Rail, Heathrow Airport, EDF Energy and the Environment Agency are planning innovation programmes.

Many tier 1 contractors that are members of the Crossrail innovation programme have implemented their own company innovation programmes. Crossrail's role has been to provide leadership through establishing the innovation programme in the first place, support through its custodianship of the programme and finally a legacy in the form of sharing its experience with industry through the Crossrail Learning Legacy website. Crossrail can be seen to have provided the encouragement to others and to have started an industry movement.

The innovation programme operates at the 'tactical' level within projects. Sharing this innovation activity between projects would start to migrate the industry towards a more strategic perspective of innovation. Ultimately, this could allow the industry to focus its capabilities and resources and to provide coherence between the organisations, including academia, to allow more significant investment in research and development and the industry to develop a coherent approach to innovation.

Other than some bilateral arrangements, there has been no pan-industry mechanism to support the emerging groundswell of innovation. Therefore, in 2015 a process was initiated to develop a way for the Crossrail experience to be developed into an industry innovation platform. During the process a number of key principles were established.

- Sharing remains the ultimate driver for the platform. It should be based on shared benefits to provide the motivation for engagement for clients and the supply chain.

- It should be led by the clients, but fully engage the supply chain in an open, collaborative format.

- It should be led and administered at an industry level so as to be independent from any one project or client. The main innovation activity should continue to be conducted by projects' own innovation programmes reflecting the value of ownership, the need for proximity to the work site and the value drivers that motivate innovation activity.

- The commitment should be commensurate with the costs of running the platform: funding of innovation activity in the first instance should remain with the projects and their supply chains.

- It should have the capacity to enable industry-level collaboration. This might include: setting industry-level innovation themes; identifying and addressing common challenges; identifying long-term approaches to trial and testing of innovations that exceed project durations; or interfacing with strategic research and development activity within universities and Innovate UK.

- Innovation should be encouraged from the earliest possible stage and clients should utilise wherever possible the tools and systems developed by the Crossrail innovation programme to minimise start-up costs.

The result of work done by Crossrail in conjunction with Thames Tideway is an infrastructure industry innovation platform called I3P, which was launched in October 2016. The concept is summarised in Figure 17, which shows the three components that make up the platform: the I3P portal, which enables the sharing of ideas and innovations; the I3P forum, which provides the collaboration vehicle for industry-level governance of the platform and is attended by all members and chaired by a client in rotation; and the I3P secretariat, which will be provided by the Knowledge Transfer Network and which will manage the portal and support the forum.

In parallel, the Construction Leadership Council has identified six themes (CLC, 2016), including innovation. Work done to develop the innovation theme during 2015 identified the need for appropriate business models to enable through-life efficiency from innovation and for the right skills to be available to realise the full value from innovation. These areas will require further work.

However, in identifying early steps that can be taken to ensure momentum (CLC, 2015: p. 3) the council recommended 


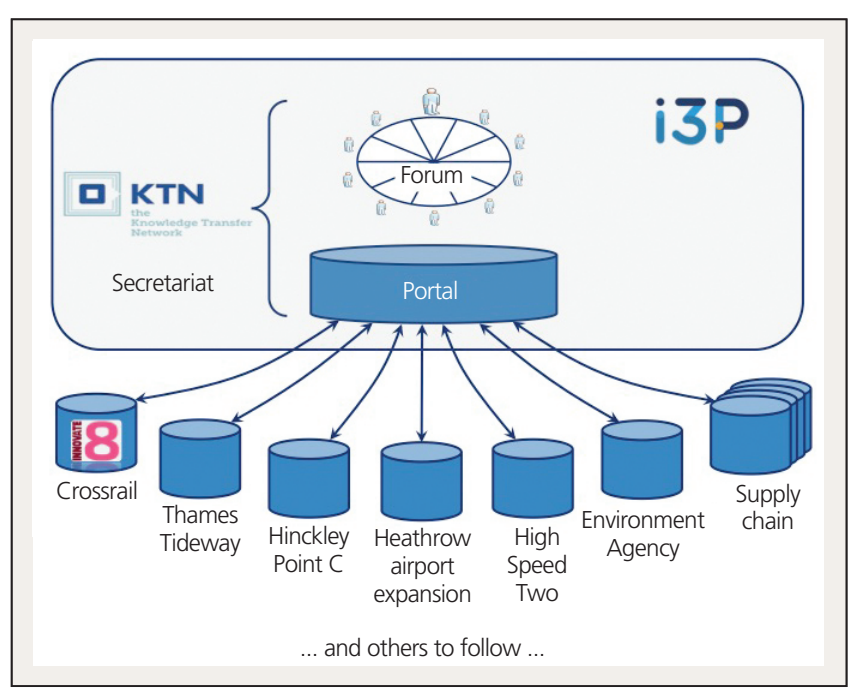

Figure 17. Infrastructure industry innovation platform I3P concept

'developing the Crossrail innovation platform into an industry model and a pan-industry innovation platform to integrate the efforts of the industry'.

I3P is now in place to provide the opportunity and the challenge for the industry to make use of it to transform the way that infrastructure is delivered and operated in the future.

\section{Conclusions}

This paper has described the key features of the Crossrail innovation programme in its mature state and suggested how the industry might develop the experience and lessons learned into a shared platform for innovation.

Fundamentally, such innovation programmes are about sharing knowledge and experience and, therefore, people are at the heart of its success. Innovation demands leadership and a new set of skills to be effective. These need to be reflected in appropriate programme governance that supports innovation through delegating responsibility and authority to the right level while fully engaging all the organisations committed to the programme.

Implementing the programme places a premium on the innovation team's resources, particularly when managing the process of transforming ideas into fielded innovations. It is critical to establish a baseline against which benefits can be assessed, although care must be taken not to stifle legitimate failure.

Incentivisation is key to the success of innovation and should extend throughout the project organisation. SMEs remain a challenging area yet one that promises great potential and which should be subject to sustained effort in the future.

The overall success of the Crossrail innovation programme has now led to several other projects adopting innovation programmes and also to the development of an industry-wide platform, I3P, to provide a focus for concerted innovation activity in the future.

\section{Acknowledgement}

The authors would like to thank all those involved in the Crossrail project for their contributions to the innovation programme and their support in developing this paper.

\section{References}

APM (Association for Project Management) (2016) APM Body of Knowledge. APM, Princes Risborough, UK. See https://www.apm.org.uk/body-ofknowledge/ (accessed 23/08/2016).

Colton CC (1824) Lacon, Or, Many Things in a Few Words: Addressed to Those who Think, 8th edn. S. Marks, New York, NY, USA.

CLC (Construction Leadership Council) (2015) Minutes. Smart Infrastructure Sub-Group, CLC, London, UK, CLC/N01/2015/P02, 21 October.

CLC (2016) Minutes. CLC, London, UK, CLC/NO2/2016/Mo2, 21 January, p. 2, section 3 .

Crossrail (2013) Crossrail Innovation Strategy. Crossrail, London, UK. See http://learninglegacy.crossrail.co.uk/documents/innovation-strategy/ (accessed 23/08/2016).

Crossrail (2016) Crossrail in Numbers: General Crossrail Information. Crossrail, London, UK. See http://www. crossrail.co.uk/news/crossrail-innumbers (accessed 23/08/2016).

Crossrail Learning Legacy (2016) Innovation Programme. Crossrail Learning Legacy, Crossrail, London, UK. See http://learninglegacy.crossrail.co.uk/ learning-legacy-themes/innovation/innovation-programme/ (accessed 23/08/2016)

Davies A, MacAulay S, DeBarro T and Thurston M (2014) Making innovation happen in a megaproject: London's Crossrail suburban railway system. Project Management Journal 45(6): 25-37.

Davies A, Dodgson M and Gann D (2016) Dynamic capabilities for a complex project: the case of London Heathrow Terminal 5. Project Management Journal 47(2): 26-46.

DeBarro T, MacAulay S, Davies A et al. (2015) Mantra to method: lessons from managing innovation on Crossrail. Proceedings of the Institution of Civil Engineers - Civil Engineering 168(4): 171-178, http://dx.doi.org/10.1680/ cien. 15.00008

Egan J (1998) Rethinking Construction - The Report of the Construction Task Force. Department of Trade and Industry, London, UK. See http:// constructingexcellence.org.uk/wp-content/uploads/2014/10/rethinking_ construction_report.pdf (accessed 10/02/2016).

Latham M (1994) Constructing the Team - Final Report of the Government / Industry Review of Procurement and Contractual Arrangements in the UK Construction Industry. HMSO, London, UK. See http://constructingexcellence.org.uk/wp-content/uploads/2014/10/ Constructing-the-team-The-Latham-Report.pdf (accessed 10/04/2016).

Rickards T (1974) Problem-Solving Through Creative Analysis. Gower, Aldershot, UK, pp. 47-48.

The Myers \& Briggs Foundation (2016) MBTI Basics. The Myers \& Briggs Foundation, Gainesville, FL, USA. See http://www.myersbriggs.org/mymbti-personality-type/mbti-basics/ (accessed 11/09/2016).

Van Gundy AB (1988) Techniques of Structured Problem Solving, 2nd edn. Van Nostrand Reinhold, New York, NY, USA, Technique 3.01, pp. 44-45.

Vernet A (2016) Crossrail Innovation Programme - Innovation Evaluation Report. Crossrail Learning Legacy, Crossrail, London, UK. See http:// learninglegacy.crossrail.co.uk/documents/crossrail-innovation-programmeevaluation-report/ (accessed 24/08/2016)

Wolstenholme A (2009) Never Waste a Good Crisis - A Review of Progress Since Rethinking Construction and Thoughts for Our Future. Constructing Excellence, London, UK. See http://constructingexcellence.org.uk/wpcontent/uploads/2014/12Molstenholme_Report_Oct_2009.pdf (accessed 10/04/2016) 